\title{
The Newly-Industrializing Developing Countries after the Oil Crisis: Reply
}

By

\author{
Bela Balassa
}

$I^{n}$

$\mathrm{n}$ his comment on my paper published in this journal [1981, pp. 142-194], Davanne suggests two modifications in the equations I have used to estimate the balance-of-payments effect of external shocks and of policy responses to external shocks: (a) actual exports and imports should be replaced by trend exports and imports in estimating terms of trade effects, and (b) additional net external financing should be re-estimated in constant prices.

ad (a): In suggesting to estimate terms of trade effects by equation ( $P_{01}^{m} M_{1}^{t}-$ $\mathrm{P}_{01}^{\mathrm{x}} \mathrm{X}_{1}^{\mathrm{t}}$ ), Davanne neglects the fact that actual export and import prices are not compatible with trend export and import quantities. Rather, one would need trend export and import prices that are consistent with the trend quantities. But these would be difficult to estimate, and we are better off with my (consistent) formulation that uses actual prices and quantities.

ad (b): As stated in the original paper, one can decompose terms of trade effects into pure terms of trade effects and unbalanced trade effects and I have also provided such estimates. Adjusting additional net external financing for unbalanced trade effects is equivalent to expressing the latter in terms of constant prices. However, my formulation is appropriate under the assumption made in the paper that world market prices would have remained at the "1972" levels in the absence of external shocks. 